\section{Commentary: Truncal root remodeling: A useful technique that can be translated to other lesions?}

\author{
Aditya K. Kaza, MD, MBA
}

Naimo and colleagues ${ }^{1}$ present their review of patients with truncal root dysfunction who underwent truncal root remodeling. The main finding of the study is that tricuspidizationtype reconstruction in quadricuspid dysfunctional valves yielded the best result over the long term. Dysfunctional aortic roots are something we are faced with more and more in the setting of congenital heart surgery; for example, dysfunctional truncal roots truncus arteriosus, dilated neoaortic root in arterial switch operations, and dilated aortic roots in conotruncal abnormalities. The authors present data regarding remodeling dysfunctional quadricuspid roots into tricuspid roots - this represents a technique that has been well described in literature to provide a durability advantage. ${ }^{2}$ Another technique that has been described includes bicuspidization of these roots to make them more competent. Other centers have reported durable, long-term freedom from repeat valve repair and replacement with this primary repair strategy. ${ }^{3}$ This type of autologous root remodeling is a valuable tool in our surgical repertoire. There are multitude of cardiac defects with dilated roots and resultant valvular dysfunction and this type of cusp resection and remodeling could be a valuable tool in making these roots less dysfunctional. In my opinion, this type of autologous remodeling and reconstruction would provide the most durable repair for growing children and thus should remain the procedure of choice. There are several technical caveats that need to be kept in mind with regard to cusp excision and remodeling, the key points being the mobilization of coronary arteries that can be unusually oriented in truncal roots and the reinforcement of the new commissure that

From the Department of Cardiac Surgery, Boston Children's Hospital, Boston, Mass. Disclosures: Author has nothing to disclose with regard to commercial support.

Received for publication Jan 22, 2020; accepted for publication Jan 23, 2020; available ahead of print Feb 1, 2020.

Address for reprints: Aditya K. Kaza, MD, MBA, Department of Cardiac Surgery, Boston Children's Hospital, 300 Longwood Ave, Bader 273, Boston, MA 02115 (E-mail: Aditya.kaza@cardio.chboston.org).

J Thorac Cardiovasc Surg 2021;161:376-7

$0022-5223 / \$ 36.00$

Copyright (c) 2020 by The American Association for Thoracic Surgery

https://doi.org/10.1016/j.jtcvs.2020.01.041

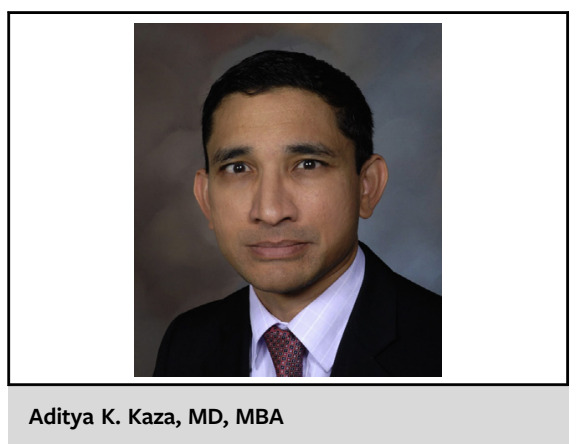

CENTRAL MESSAGE

Can truncal root remodeling be translated to other lesions?

is created after cusp resection because this area is usually under some tension and would benefit from reinforcement.

The focus of the article by Naimo and colleagues ${ }^{1}$ is remodeling related to reducing the number of cusps and thus gaining a functional advantage. The group has shown good results with using this technique, and highlights the advantage of having a competent aortic valve from the neonatal period onward. Among the important take-home messages is the decision to tackle the truncal valve at the time of primary repair if the level of insufficiency is moderate or greater. There is some operator variability with regard to grading truncal valve insufficiency with echocardiography, and it may be something that is better resolved with additional imaging if there are significant questions about the grade of insufficiency. This are the type of objective data that could help surgeons decide on the best treatment for these complex neonates. The Melbourne group has a track record of publishing long-term follow-up on patients with complex defects. Along these lines, their latest article provides good follow-up data and analysis of intervention-free survival. Although the early mortality in truncal valve repair patients was high (14\%), the 15-year survival was very high: $77 \%$. The more important data are the freedom from truncal valve operations: $30 \%$ at 15 years. This points to the fact that these valves are intrinsically dysfunctional and may need to be eventually re-repaired or replaced. The authors further show that the tricuspidization technique provides a reintervention-free period of $64 \%$ at 10 years. In other words, if the valve morphology is such that a quadricuspid truncal valve is insufficient, the best repair technique may be remodeling with cusp resection. Once again, good quality echocardiography can help guide surgeons identify the ideal technique for making valves more competent. 


\section{References}

1. Naimo PS, Fricke TA, Lee MGY, d'Udekem Y, Brink J, Brizard CP, et al. The quadricuspid truncal valve: surgical management and outcomes. J Thorac Cardiovasc Surg. 2021;161:368-75.
2. Myers PO, Bautista-Hernandez V, del Nido PJ, Marx GR, Mayer JE, Pigula FA, et al. Surgical repair of truncal valve regurgitation. Eur J Cardiothorac Surg. 2013;44:813-20.

3. Kaza AK, Burch PT, Pinto N, Minich LL, Tani LY, Hawkins JA, et al. Durability of truncal valve repair. Ann Thorac Surg. 2010;90:1307-12.
See Article page 368.

\section{Commentary: This looks like a great hammer... which nails should we pound?}

\author{
Paul M. Kirshbom, MD
}

Naimo and colleagues from the Royal Children's Hospital in Melbourne, Australia, ${ }^{1}$ revisit their series of truncus arteriosus patients dating back to $1979 . .^{2,3}$ In this third installment, they focus on the management of patients with a quadricuspid truncal valve (TV) with particular attention to the technique of tricuspidization of the valve in the setting of significant TV regurgitation. The study population included 56 patients with quadricuspid valves who underwent repair between 1979 and 2018, 14 of whom underwent concomitant TV repair or replacement at the time of the initial truncus arteriosus repair.

The overall survival rate for the group was comparable to the Society of Thoracic Surgeons database review of truncus arteriosus patients published in $2012,{ }^{4}$ with operative mortality in the $10 \%$ range for those who did not require TV repair or replacement at the initial procedure. However, the patients presented in the current review had considerably better outcomes if they underwent concomitant TV repair, with $14 \%$ early mortality ( 2 out of 14 ) as opposed to a reported $30 \%$ mortality in the Society of Thoracic Surgeons database review.

\footnotetext{
From the Division of Pediatric Cardiothoracic Surgery, Sanger Heart and Vascular Institute, Atrium Healthcare, Charlotte, NC.

Disclosures: Author has nothing to disclose with regard to commercial support.

Received for publication Jan 15, 2020; accepted for publication Jan 15, 2020; available ahead of print Feb 1, 2020

Address for reprints: Paul M. Kirshbom, MD, Division of Pediatric Cardiothoracic Surgery, Sanger Heart and Vascular Institute, Atrium Healthcare, Charlotte, NC 28203 (E-mail: Paul.kirshbom@ carolinashealthcare.org).

J Thorac Cardiovasc Surg 2021;161:377-8

$0022-5223 / \$ 36.00$

Copyright (C) 2020 by The American Association for Thoracic Surgery

https://doi.org/10.1016/j.jtcvs.2020.01.040
}

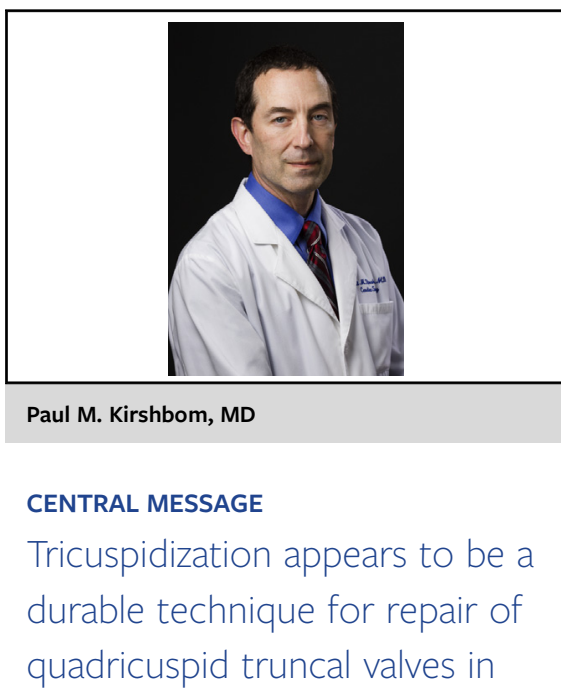

The truncus arteriosus.

strengths of this report include the excellent illustrations showing the various repair techniques, with particular attention to the tricuspidization options, and the relatively complete follow-up of the patient population. However, the long time period required to accrue this many patients at a single institution makes it difficult to accept the statement that there were no era effects. This is clearly a problem for any long-term retrospective study, but it is particularly difficult for complex neonatal repairs given the rapid changes that have taken place over the past decades. For example, in this report the age of the patients at the time of surgery changed dramatically over the study period (age 70 days in the 1980s vs age 8 days in the most recent decade) and the fact that there were no tricuspidizations during the earliest decade makes it very difficult to determine just how important the era effects really were.

Despite these questions, it is clear that the authors' outcomes were excellent using tricuspidization in the selected patients in whom they utilized the technique. Unfortunately, the relatively small number of patients and the clear era 